\title{
Use of Complementary and Alternative Medicine for Menopause Symptoms and Its Effect on Quality of Life Among Turkish Women
}

\author{
MSN Gokgoz N and Pinar G* \\ Department of Nursing, Faculty of Health Sciences, Ylldırım Beyazıt University,Ankara, Turkey
}

*Corresponding author: Gul Pinar, Associate Professor, Department of Nursing, Faculty of Health Sciences, Yildirim Beyazit University, Ankara, Turkey.

Received Date: August 05, 2020

Published Date: October 30, 2020

\begin{abstract}
Introduction: The research was conducted to determine complementary and alternative medicine (CAM) applications that women resorted for menopause symptoms and the effect of this on life quality.

Methods: The descriptive and cross-sectional study was performed on 270 women in 2014. Data were collected using The Survey Form and The Menopause-Specific Quality of Life Scale.

Results: Average age of women in the study was $54.2 \pm 5.0$. It was determined that women in menopause stage experienced frequent hot flushes (86.9\%), vaginal dryness/dyspareunia (81.7\%), muscle-joint ache $(70.4 \%)$ and decrease in sexual desire (65.7\%). CAM use ratio was found to be $62.2 \%$. It was determined that $10 \%$ of women applied these methods by consulting a health team. It was found that the biologically based of therapies $(90.5 \%)$, with the use of herbal medicine, is the main practice used during menopause, then the mind-body interventions (83.3\%) as the prayer of healing and the manipulation body-based methods (34.5\%), exercises and acupuncture are also cited with common practices. It was determined that life qualities of women using CAM were better in vasomotor, psychosocial, physical and sexual areas $(\mathrm{p}<0.05)$.

Conclusion: More than half the women had used a CAM therapy in the study. CAM methods used by women are beneficial considerably (53\%$90 \%$ ) for menopause symptoms. It is suggested that women in this stage, when menopause symptoms are controlled better by CAM use, should receive training and consultancy about safe CAM use and further studies are conducted.
\end{abstract}

Key words: Menopause; Menopause Symptoms; CAM Methods; Quality of life

\section{Introduction}

The term menopause is defined as the permanent cessation of menstruation resulting from the loss of ovarian follicular activity. The World Health Organization (WHO) defines menopause after 12 consecutive months of amenorrhea for which there is no other obvious pathological or physiological cause [1]. Along with the decrease of estrogen level during menopause stage; in the early phase, hot flush, sweating, and attention and memory problems are experienced, and in the late phase, problems are experienced such as sexual dysfunction, urogenital atrophy, vulva itching, dyspareunia, uterine bleeding, urinary incontinence, fertility loss, defect in body image, cardiovascular system disorders, and osteoporosis [2]. These are combined with social and symbolical meanings, and thus quality of life can be affected negatively [3]. It is estimated that 1.2 billion women will be in the menopause and post-menopause stages by 2030 [1]. Thus, a great number of women will be enduring the problems of menopause and the resulting lower quality of life. 
The WHO defines quality of life as individuals' perception of their position in life in the context of the culture and value systems in which they live and in relation to their goals, expectations, standards, and concerns [4]. Various studies showed that women in the menopause stage experienced hot flashes and sweats $(41.6 \%$ $71.2 \%)$ considerably. However, joint and muscle disorders (80.1\%), physical and mental exhaustion (67.1\%), insomnia (\%65), vaginal dryness and pain with intercourse (37.9\% - 57\%) are included among other problems in the studies [5-9]. Augmentation of the time spent in menopausal stage and life quality of women affected unfavorably by menopause-dependent health problems make the treatment inevitable [7]. In the conducted studies, it is reported that medical treatments used in the management of menopause symptoms have an important clinical role however due to their complex biological effects and their limited benefits against risks, they are not preferred by many women $[10,11]$. Complementary and alternative medicine (CAM) is a group of diverse medical and health care systems, practice, and products that are not presently considered to be part of conventional medicine. Although their reliability is not revealed completely, during the recent years, women prefer CAM methods which they believe that they are safer and natural in order to relieve menopause symptoms $[10,12,13]$.

According to 2014-2023 "Traditional Medical Strategy" report of the WHO, it is reported that interest in CAM use increased in many developed countries and its use became widespread (\%40-\%80) [13]. The conducted studies show that CAM use frequency during menopause stage changes between $37.4 \%$ and 55.0\% [14-16]. Women resort to CAM methods that they think are effective in the management of vasomotor symptoms especially [5]. The conducted studies reported that phytoestrogens and physical-mental methods were preferred by women most frequently $[4,17,18]$. Nevertheless, it was determined that the studies evaluating the relationship of CAM use during menopause stage and life quality are limited. Some of these studies reported that traditional acupuncture is effective on vasomotor symptoms, yoga caused positive changes in life quality of women and Mediterranean diet and physical exercise had positive effects on haemostatic balance and life quality $[2,7,13,19$ 21]. Silva et al reported in their study that women who experienced low sleep quality due to fibromyalgia during menopausal stage improved their sleep quality by passive body warming method [22].

According to the literature, although there are various studies in Turkey about the methods to cope with menopausal symptoms and CAM use in menopause, there are limited numbers of researches to determine the effect of CAM use on life quality.

Aim: Purpose of this study was determining CAM applications used by women for menopausal symptoms and the effect of this on life quality.

Research Questions: 1) What is the CAM use rate during menopausal stage? 2) What are CAM-methods used during menopausal stage? 3) Is there a relationship between CAM use and the score averages of Menopause-Specific Quality of Life Scale (MENQOL)?

\section{Methods}

\section{Study design, setting, period, population, and sample size}

This descriptive and cross-sectional study was conducted during February 15-September 252014 in a private university hospital, menopause polyclinic in Turkey. 800 women who applied to the menopause polyclinic of this hospital during one year made up the universe of the study. 270 women made up the research sample with $95 \%$ confidence interval and $\pm 5 \%$ deviation according to the formula to estimate the sampling number in cases when the universe is known by considering Ozdamar's study [23]. The women were included in the study by selection with simple random sampling method. 168 women out of 270 women in the sampling indicated that they used CAM and 102 women indicated that they did not use any CAM method. Until this number is reached, the women fitting the research criteria among those who applied to the clinic were included in the study group in a randomized fashion. Only 6 women did not wish to participate in the study among the determined ones.

\section{Exclusion and inclusion criteria}

Inclusion criteria: in the framework of menopause definition of the WHO, women who 1) did not have menstruation for at least 12 months, 2) entered menopause by surgical intervention by having total abdominal hysterectomy with bilateral salpingooophorectomy, 3) did not pass 65 years of age which is accepted as the old age limit by the WHO, 4) did not have auditory or mental disability, 5) are open to communication and collaboration, 6) are volunteers to participate in the study were included.

Exclusion criteria: 1) receiving hormone replacement therapy, 2) women with a diagnosed psychiatric disease and serious chronic diseases (malignancies, neurological conditions, immediate deterioration of chronic illness, etc.) were excluded.

\section{Variables}

Independent variables: socio-demographic, obstetric and menopausal characteristics.

Dependent variables: MENQOL score.

\section{Instruments}

The researcher completed the data collection forms by face-toface interview method and each interview lasted 15 minutes. The instruments used include:

The Survey Form: It consists of 33 questions enabling determination of individual characteristics of women ( 9 questions), obstetric and general health story (7 questions), menopausal characteristics (8 questions), CAM use (past 6 months),used CAM methods, CAM using reasons and the symptoms they affect, 
knowledge on CAM use information source, the effectiveness of the methods ( 9 questions) and their side effects and sharing with health team[3,12,14,15,20]. Pre-application of the survey was carried out on 27 women in order to determine the clarity of the data collection form. It was determined after the pre-application that there was no difficulty in the understanding of the questions in the data collection form.

CAM methods were defined as follows in the survey form: CAM is a group of diverse medical and health care systems, practice, and products that are not presently considered to be part of conventional medicine. The National Center for Complementary and Alternative Medicine (NCCAM, 2015) and WHO classifies were used to determine CAM therapies categories in the study $[13,24]$;

1. Alternative medical systems (include homeopathic medicine and naturopathic medicine, ayurveda)

2. Mind-body interventions (include meditation, yoga, prayer, mental healing, acupuncture, and therapies that use creative outlets such as art, music, or dance).

3. Biologically based therapies (include natural herbs, foods, and vitamins)

4. Manipulative and body-based methods (include chiropractic or osteopathic manipulation, reflexology and massage).

5. Energy therapies (include qi gong, reiki, cupping and therapeutic touch)

4.4.2.The MENQOL Scale: It is a life quality scale related to the health state unique to menopause and developed by Hilditch, Lewis, and Peter A et al [25] in 1996. It was adapted to Turkish society in 2007 by Kharbouch and Sahin, and the validity and reliability study was conducted [26]. The scale is a Liker type consisting of 29 questions. It is made of four sub areas as vasomotor (1-3), psychosocial (4-10), physical (11-26) and sexual (27-29). Each sub areas are listed from scale 1 to 6 in scale scoring. As the score increases, the severity of the complaint increases and life quality drops. Total scale scoring is not estimated [26]. Cranach's alpha value of the scale is 0.73-0.88'dir.In this study, the Cranach's Alpha reliability coefficient was found to be 0.96 .

The Ethics Committee of Private University Hospital approved this study. Legal permission was also obtained from the hospital management. All participants signed a written informed-consent form before enrolling in the study. Rules specified in the Helsinki Declaration were observed in the data collection phase.

\section{Statistical Analysis}

The data were evaluated with the Statistical Package for the Social Sciences (SPSS) 20 package program. The statistical analysis was carried out using descriptive analyses (percentage distribution, mean and standard deviation), chi-square and Mann-Whitney U test. The statistical level of significance was adopted to be $\mathrm{p}<0.05$.

\section{Results}

The average age of the women who participated in the research was $54.2 \pm 5.0$. It was determined that $95.9 \%$ of the women were married, $45.2 \%$ of them were high school graduates and had higher education, $27.8 \%$ worked in an income bringing job, and $72.6 \%$ of them had good economic status. Average menopause age of the women was $46.9 \pm 1$.9. It was determined that $95.2 \%$ of them entered menopause naturally. It was determined that health problems of the women experienced during menopause stage were in turn; sudden hot flushes (86.9\%), vaginal dryness/dyspareunia (81.7\%), muscle-joint ache (70.4\%), reduced sexual desire $(65.7 \%)$ and sleep problems (64.8\%) (Table1).

Table 1: Distribution of individual characteristics of women $(n=270)$.

\begin{tabular}{|c|c|}
\hline Individual characteristics & Mean \pm SD \\
\hline Age & $54.02 \pm 5.0$ \\
\hline Menopause age & $46.9 \pm 1.9$ \\
\hline Marital status & N (\%) \\
\hline Single & $2(0.8)$ \\
\hline Married & $259(95.9)$ \\
\hline Divorce & $9(3.3)$ \\
\hline \multicolumn{2}{|c|}{ Education Status } \\
\hline Literate & $17(6.3)$ \\
\hline Primary education & $131(48.5)$ \\
\hline High school or higher & $122(45.2)$ \\
\hline \multicolumn{2}{|c|}{ Employment Status } \\
\hline Employed & $75(27.8)$ \\
\hline Unemployed & $148(54.8)$ \\
\hline Retired & $47(17.4)$ \\
\hline \multicolumn{2}{|c|}{ Menopause Status } \\
\hline Natural menopause & $257(95.2)$ \\
\hline Surgical menopause & $13(4.8)$ \\
\hline \multicolumn{2}{|c|}{ Menopausal Complaints* } \\
\hline $\begin{array}{l}\text { Having hot flushes-experiencing } \\
\text { sweat }\end{array}$ & $185(86.9)$ \\
\hline Vaginal dryness / dyspareunia & $174(81.7)$ \\
\hline Joint and muscle pain & $150(70.4)$ \\
\hline Loss of sexual desire & $140(65.7)$ \\
\hline Having sleeping problems & $138(64.8)$ \\
\hline Others ** & $69(32.4)$ \\
\hline
\end{tabular}

* $\mathrm{n}$ number increased due to multiple answering to these questions ** Others; change in the appearance of skin (\%68.5), headache (\%67.1), feeling memory fading (\%53.5), energy decrease feeling (\%51.6), feeling tired and worn out (\%48.4).

It was determined that $62.2 \%$ of the women resorted to CAM methods to alleviate their menopause complaints and $72.6 \%$ used these methods for 3 years and longer. It was determined that $42.3 \%$ of the women obtained information on CAM method from women who applied CAM, $31.6 \%$ from mass communication devices, 
$16.1 \%$ from friends and relatives, and $10 \%$ from health providers (Table 2).

Table 2: Distribution of characteristics use of CAM for menopausal symptoms women's.

\begin{tabular}{|c|c|c|}
\hline Characteristics & $\mathbf{n}$ & $\%$ \\
\hline \multicolumn{3}{|c|}{ Use of CAM } \\
\hline Yes & 168 & 62.2 \\
\hline No & 102 & 37.8 \\
\hline \multicolumn{3}{|c|}{ Lifetime use of CAM } \\
\hline 6 month-1 year & 16 & 9.5 \\
\hline 2 year & 30 & 17.9 \\
\hline 3 year and over & 122 & 72.6 \\
\hline \multicolumn{3}{|c|}{ Information source about CAM } \\
\hline CAM practitioners & 71 & 42.3 \\
\hline Media & 53 & 31.6 \\
\hline Friends-Relatives & 26 & 16.1 \\
\hline Health providers & 18 & 10 \\
\hline
\end{tabular}

It was found that the biologically based of therapy (90.5\%), with the use of herbal medicine, is the main practice used during menopause, then the mind-body interventions (83.3\%) as the prayer of healing and the manipulation body-based methods (34.5\%), exercises and acupuncture are also cited with common practices (Table 3).

Table 3: Distribution of effectiveness and CAM methods ( $N=168)$.

\begin{tabular}{|c|c|c|}
\hline Categories of CAM** & n (\%) * & Effective \\
\hline $\begin{array}{c}\text { Biologically based } \\
\text { therapies }\end{array}$ & $152(90.5)$ & $143(94.1)$ \\
\hline Soy Products & $77(45.8)$ & $55(71.4)$ \\
\hline Black Cohosh & $44(26.1)$ & $32(72.7)$ \\
\hline Nigella sativa & $40(23.8)$ & $25(62.5)$ \\
\hline Peppermint oil & $22(13.0)$ & $10(45.5)$ \\
\hline Flax seed & $17(10.1)$ & $7(88.2)$ \\
\hline Sage & $17(10.1)$ & $10(45.5)$ \\
\hline Thyme Tea & $16(9.5)$ & $6(37.5)$ \\
\hline Tipton's weed & $15(8.9)$ & $5(33.3)$ \\
\hline Achillea millefolium & $15(8.9)$ & $7(46.6)$ \\
\hline Camomile Tea & $13(7.7)$ & $3(23.0)$ \\
\hline Green Tea & $13(7.7)$ & $10(41.1)$ \\
\hline Linden & $10(5.9)$ & $2(20.0)$ \\
\hline Vitamin (tablets) & $14(8.3)$ & $4(28.6)$ \\
\hline $\begin{array}{c}\text { Mind-body } \\
\text { interventions }\end{array}$ & $140(83.3)$ & $132(94.3)$ \\
\hline Pray & $136(80.9)$ & $129(94.9)$ \\
\hline Music therapy & $4(2.4)$ & $2(50.0)$ \\
\hline $\begin{array}{c}\text { Manipulation and } \\
\text { body-based methods }\end{array}$ & $58(34.5)$ & $43(74.1)$ \\
\hline Exercises & $27(16.1)$ & $18(66.7)$ \\
\hline Acupuncture & $23(13.7)$ & $17(73.9)$ \\
\hline Hydrotherapy & $6(3.6)$ & $6(100.0)$ \\
\hline
\end{tabular}

\begin{tabular}{|c|c|c|}
\hline Massage & $2(1.1)$ & $2(100.0)$ \\
\hline Energy therapies & $5(3.0)$ & $5(100.0)$ \\
\hline Therapeutic touch & $3(1.8)$ & $3(100.0)$ \\
\hline Cupping therapy & $2(1.2)$ & $2(100.0)$ \\
\hline
\end{tabular}

*n number increased due to multiple answering to these questions

**1) biologically based therapies; herbs, dietary supplements or vitamins; 2) mind-body interventions; meditation, prayer, healing or support groups; 3) manipulation and body-based methods; massage, exercises or osteopathy and 4) energy therapies (i.e. biofield therapies such as Reiki or therapeutic touch ${ }^{9}$ ).

When the reasons for CAM use were examined, in turn, it was stated by the women that; it decreased hot flush and sweating complaints (28.6\%), it was natural and safe $(27.4 \%)$, it reduced aches $(22.6 \%)$, and it helped physical and mental fatigue (8.8\%).

CAM methods used by women are beneficial considerably (biologically based methods; 90\%, mind-body based $80 \%$, and manipulation-based therapy 53\%) for menopause symptoms.

CAM use by the women who worked in an income-earning job was $38.7 \%$, and this ratio was $71.6 \%$ for the women who did not work. Higher level of CAM use in the unemployed group was found to be statistically significant $\left(x^{2}=24.1, p=0.0001\right)$. Although CAM use was greater in the advanced age group $\left(x^{2}=0.08, p=0.956\right)$ and in the group who had low educational level $\left(x^{2}=5.26, p=0.071\right)$, the difference between them was not significant statistically $(\mathrm{p}<0.05)$.

Table 4: Distribution of mean scores of MENQOL.

\begin{tabular}{|c|c|c|c|c|}
\hline $\begin{array}{c}\text { MENQOL- } \\
\text { Subscales }\end{array}$ & Mean & SD & Min & Max \\
\hline Vasomotor & 3.3 & 1.3 & 0 & 6 \\
\hline Psychosocial & 1.4 & 1.1 & 0 & 4.1 \\
\hline Physical & 2.2 & 1.1 & 0 & 4.6 \\
\hline Sexual & 3.2 & 1.5 & 0 & 6 \\
\hline
\end{tabular}

Table 5: Distribution of mean scores of MENQOL according to use of CAM.

\begin{tabular}{|c|c|c|c|}
\hline \multirow{2}{*}{} & \multicolumn{3}{|c|}{ Use of CAM } \\
\cline { 2 - 4 } & $\begin{array}{c}\text { Yes Mean } \\
\text { (min-max) }\end{array}$ & $\begin{array}{c}\text { No Mean } \\
\text { (min-max) }\end{array}$ & Analysis * \\
\hline Vasomotor & $2.88(0.00-6.00)$ & $3.96(0.33-6.00)$ & $-6.9 ; 0.0001$ \\
\hline Psychosocial & $1.06(0.00-3.86)$ & $1.92(0.00-4.14)$ & $-5.4 ; 0.0001$ \\
\hline Physical & $1.91(0.00-4.25)$ & $2.76(0.00-4.56)$ & $-5.6 ; 0.0001$ \\
\hline Sexual & $3.02(0.00-6.00)$ & $3.56(0.0-6.00)$ & $-3.1 ; 0.0001$ \\
\hline
\end{tabular}

When the score averages of the subgroups of the participants' MENQOL were scrutinized; vasomotor area was $3.3 \pm 1.3(0-6)$, psychosocial area was $1.4 \pm 1.1(0-4.1)$, physical area was $2.2 \pm 1.1$ (04.6), and sexual area average was $3.2 \pm 1.5(0-6)$ (Table 4). As a result of the analysis, it was determined that the women who entered menopause by surgical means experienced more physical $(\mathrm{z}=-4.10$, $\mathrm{p}=0.0001)$ and sexual problems $(\mathrm{z}=-2.12, \mathrm{p}=0.034)$ and their life quality was affected unfavorably. Menopausal symptoms in the study group among CAM using women were observed less. Accordingly, it 
was determined that vasomotor $(\mathrm{z}=-6.9, \mathrm{p}=0.0001)$, psychosocial $(\mathrm{z}=-5.4, \mathrm{p}=0.0001)$, physical $(\mathrm{z}=-5.6, \mathrm{p}=0.0001)$ and sexual life $(\mathrm{z}=-$ 3.1, $\mathrm{p}=0.0001$ ) qualities were higher (Table 5). According to CAM methods, in the comparison of MENQOL subscales score averages, it was found that life quality was higher in the women who used biological method the most $(\mathrm{z}=-3,15 ; \mathrm{p}=0.002)(\mathrm{p}=0.002)$.

\section{Discussion}

The conducted studies showed that women in menopause stage experienced significant level of hot flushes and sweating problems (\%41.6-\%71.2) [9,27]. Hot flashes and sweating problems $(66.5 \%$ and $65.2 \%$, respectively) were determined to be the most frequently experienced health problems by women in menopausal stage in Turkey as well [28]. It was also determined in our study similarly that the women had hot flashes-sweats (86.9\%). In the researches, the ratio of women who experience vaginal dryness changes between $37.9 \%$ and $57 \%$ [9,29,30]. In our study, dyspareunia/ vaginal dryness complaint was higher than that in other studies (81.7\%) (Table 1).

During the recent years, women who wish to fix their acute health problems and improve their life quality resort to CAM because of its easy access and being an alternative to medical treatment [31,32]. In the study of Gartoulla et al [5], it was reported that the interest of Australian women in menopause stage to CAM use increased. In the study of Sluijs et al [33], CAM use rate in menopause stage was $53.8 \%$. This ratio changed between $31 \%$ to $82.5 \%$ in the literature search to determine CAM use rates [6,7]. In the studies performed in the national level, CAM use rate of women in menopause stage changed between $29.9 \%$ to $37.4 \%$ [14,34]. In our study, it was determined that $62.2 \%$ of the women resorted to CAM methods. CAM use rate was found to be higher in our study to be different than other research results.

In a literature search conducted to evaluate the variation of the used methods in different countries; it was seen that the first method resorted by women was biological-based methods generally [5,32,33]. The studies conducted in Turkey reported that women in menopausal stage preferred herbal treatments especially to cope with their problems [14,34] Nevertheless, in a study making an evaluation based on race/ethnic groups, it was reported that ginseng as biologically based therapy was used frequently in all groups, Chinese tea, vegetarian diets, and soybean fortifications were used by Chinese and Japanese women and white women and Afro-American women resorted to praying more frequently than other groups did. Also, manipulative-body based methods (massage, acupressure, and reflexology) and mindbody methods (meditation, yoga, acupuncture, mental imagery or progressive relaxation) were used by Chinese women [35]. Some of these results are similar to the literature in terms of especially herbal use and adaptation of praying in our study. Various herbal supplements and spiritual therapies as religious healing which can allow positive influences on health are well known among the community in Turkey, generally used by adult female. Cultural beliefs and practices often lead to home remedies or consultation with religious healers in our country. On the other hand, one might argue this is a true reflection of the patients' culture where prayer and spiritual believes are part of people's everyday life and may not be included in CAM. The use of other methods (such as acupuncture, yoga, homeopathy, meditation or hypnotherapy) did not find adequate support for its use in menopausal symptoms. We suggest that there is a cultural background underlying these findings. Successful programs in dealing with menopausal symptoms need to include the establishment of a community-based intervention strategy including health providers to educate people about use of CAM methods. It is indicated in the literature that CAM-using women resorted to this method by media, the internet, and with the suggestion of friends and family, and most of CAM users did not collaborate with health providers $[16,36]$. Our study results are compatible with the literature in this aspect and only $10 \%$ of CAM using women collaborated with health providers (Table 2).

Cardin et al reported in their study that women sought advice of herbalists, dieticians and homeopaths for preference of CAM use. In the same study, it was emphasized that the difficulties experienced by women to receive information about CAM should be overcome by education in health institutions [32]. In Turkey, the Regulation of Traditional, CAM Applications regulated the procedures and principles about the application of these methods and the involvement of the persons and organizations that are not health professionals in CAM applications is attempted to be prevented [37].

Women generally prefer treatment methods consorting with their cultural values in the selection of a CAM method during menopause stage. Natural estrogen resources, meditation, acupuncture and exercise is preferred by women to alleviate menopausal complaints. Soya products and black snakeroot is reported to be beneficial in vasomotor symptoms, and ginseng tea, evening primrose oil, licorice root and polemonium is useful for physical and psychological problems [24,38,39]. In other studies, biology-based plant therapy preferences of women in menopausal stage ranged between $5 \%$ to $29.9 \%[5,14,27,34]$. In our research, the widely preferred CAM method was biological treatments (90.5\%) and it was determined that soya products were used the most (45.8\%) (Table 3). Similarly, it was reported in the other researches that women preferred soya products to alleviate menopause complaints $[7,14]$. Nevertheless, phytoestrogen-based products can be beneficial in easing the menopause symptoms however there are not adequate studies reporting their complications [40]. Based on all these findings, it is observed that interest in phyto therapy among women is intense. In this sense, it is crucial that CAM methods are supported by evidence-based researches. 
Body-mind treatments have a crucial place in the management of menopause symptoms. The second most preferred CAM method in our research was determined to be body-mind treatments (83.3\%) (Table 3). Brett et al determined in their study that $25 \%$ of women used body-mind methods to deal with the menopause problems [17]. Lunny and Fraser [18] reported in their research that there were relaxation techniques (57\%), yoga/meditation (37.6\%) and praying (35.7\%) among body-mind methods preferred by women. It is remarkable that in our study, majority of the women (80.9\%) preferred "praying method" among the bodymind treatments (Table 3). It is natural that resorting to religious applications intensely for dealing with health problems complies with the socio-cultural structure of Turkey.

Although energy treatments among CAM methods were used in a limited level in our research (3.0\%), the women evaluated it as having the highest effectiveness. Body and mind treatments and biology-based treatments followed this (Table 3). Whereas there are limited numbers of studies evaluating the effectiveness level based on CAM methods in the literature, it was determined in a research conducted on German women that the used CAM methods were perceived as effective in the rate of $45.5 \%$ to $84.5 \% .5$ Lunny and Fraser [18] determined in their study that the methods benefited the most by women in menopause stage were praying/ spiritual healing, relaxation techniques, consultancy/therapy and treatment, touching/Reiki.

The conducted studies manifest that menopause-based physical, psychological and social changes affect life quality of women unfavorably $[3,12,16,20]$. It can be concluded that when the results of our study were compared with those of the other studies, the life quality score averages that we gathered were lower (Table 4). In our study, it is thought that especially alleviation of life quality in sexual area is because women in menopause stage in Turkey see the problems about their sexual life as a natural outcome of the process and don't search solution.

It was found in our study that life quality of the CAM using women was higher in comparison to the women who don't use it in the areas of vasomotor, psychosocial, physical and sexual $(\mathrm{p}<0.05)$ (Table 4). Reed et al observed in their study that regularly performed "yoga" improved sleep quality and physical area life quality of women in menopause stage by regular exercise [20]. It is reported in the literature that women with postmenopausal symptoms can improve their life quality with exercise [25]. In Thompson's study [41], it was determined that homeopathy treatment improved life quality of women who were in menopausal stage and had breast cancer in especially vasomotor area. Taovani et al [42] determined that therapeutic massage and aromatherapy controlled psychological indications of menopause and regulated women's life. Caputo and Costa reported in their literature review that physical activity was essential for improving life quality of postmenopausal women with osteoporosis [43]. Although the results of the studies support our research finding, they illustrated that CAM methods influenced life qualities of the women in menopause stage favorably.

\section{Conclusion}

In the study, it was determined that women in menopausal stage especially experienced hot flushes and sweating intensely. It is thought that CAM methods used by women are beneficial considerably (53\% - 90\%) for menopause symptoms. Life quality of women who use CAM methods was determined to be better in comparison to women who do not use them. CAM may contribute positively to menopausal period by helping to relieve some of symptoms. It is suggested that CAM methods are supported by evidence-based researches.

\section{Limitations}

This study has several limitations. The validity of the findings is dependent on the individual's memory and accuracy in reporting CAM use. Women who applied to the menopause polyclinic of the hospital and have an interest in CAM might have been more likely to take the time to complete the questionnaire. The sample in this study reflects only one area of Turkey and the findings should be limited to this population. However, the fact that there are only a few studies in the international field and that a similar study has not been done in our country makes our work unique.

\section{Author contributions}

Gokgoz N, and Pinar G conceived and designed the study. Gokgoz N performed the study. Gokgoz N and Pinar G performed the statistical analysis and wrote the manuscript. Both of authors read and approved the final manuscript.

\section{Acknowledgment}

The authors would like to thank all the women and hospital staff who participated in this study.

\section{Conflict of Interest}

The authors declare that they have no competing interest.

\section{References}

1. (2014) World Health Organization. Research on the menopause in the 1990s.

2. Ertüngealp E, Seyisoğlu H (2000) Menopause and Osteoporosis. Istanbul, Menopause and Osteoporosis Society Press: 24-31.

3. Bener A, Falah A (2014) A measurement-specific quality-of-life satisfaction during premenopause, perimenopause and postmenopause in Arabian Qatari women. J Midlife Health 5(3): 126-134.

4. (2014) World Health Organization. WHOOQL measuring quality of life.

5. Gartoulla P, Davis SR, Worsley R, Bell RJ (2015) Use of complementary and alternative medicines for menopausal symptoms in Australian women aged 40-65 years. MedJ Aust 203: 146e.1-6.

6. Peng W, Adams J, Sibbritt DW, Frawley JE (2014) Critical review of complementary and alternative medicine use in menopause: focus on prevalence, motivation, decision-making, and communication. Menopause 21(5): 536-548. 
7. Posadzki P, Lee MS, Moon TW, Choi TY, Park TY, et al. (2013) Prevalence of complementary and alternative medicine (CAM) use by menopausal women: a systematic review of surveys. Maturitas 75(1): 34-43.

8. Sharma S, Tandon VR, Mahajan A (2007) Menopausal Symptoms in Urban Women. JK Science 9: 13-17.

9. Rahman SA, Zainudin SR, Mun VL (2010) Assessment of menopausal symptoms using modified Menopause Rating Scale (MRS) among middle age women in Kuching, Sarawak, Malaysia. Asia Pac Fam Med 9(1): 5.

10. Chiu HY, Pan CH, Shyu YK, Han BC, Tsai PS (2015) Effects of acupuncture on menopause-related symptoms and quality of life in women in natural menopause: a meta-analysis of randomized controlled trials. Menopause 22: $234-244$

11. Kim MY, Choi SD, Ryu A (2015) Complementary and Alternative Therapy Effective for Women in the Climacteric Period? J Menopausal Med 21: 28-35.

12. Jayabharathi B, Judie A (2014) Complementary health approach to quality of life in menopausal women: a community-based interventional study. Clin Interv Aging 9: 1913-1921.

13. (2014) World Health Organization. Traditional Medicine Strategy 2014 2023.

14. Ege E, Kal HE, Altuntuğ K (2014) The use of alternative methods in reducing menopausal complaints in Turkey. Afr J Tradit Complement and Altern Med 11(2): 295-300.

15. Sluijs CP, Bensoussan A, Liyanage L, Shah S (2007) Women's health during mid-life survey: the use of complementary and alternative medicine by symptomatic women transitioning through menopause in Sydney. Menopause 14(3): 397-403.

16. Hill-Sakurai LE, Muller J, Thom DH (2008) Complementary and alternative medicine for menopause: a qualitative analysis of women's decision making. J Gen Intern Med 23(5): 619-622.

17. Brett KM, Keenan NL (2007) Complementary and alternative medicine use among midlife women for reasons including menopause in the United States: 2002. Menopause 14(2): 300-307.

18. Lunny CA, Fraser SN (2010) The use of complementary and alternative medicines among a sample of Canadian menopausal-aged women. J Midwifery Womens Health 55(4): 335-343.

19. Dodin S, Blanchet C, Marc I, Ernst E, Wu T, et al. (2013) Acupuncture for menopausal hot flushes. Cochrane Database Syst 2013(7): CD007410.

20. Reed SD, Guthrie KA, Newton KM, Katherine M Newton, Garnet L Anderson et al. (2014) Menopausal quality of life: RCT of yoga, exercise, and omega-3 supplements. Am J Obstet Gynecol 3: 244.e1-244.e11.

21. Llaneza P, González C, Fernández-Iñarrea J, Alonso A, Díaz F, et al. (2012) Soy isoflavones improve insulin sensitivity without changing serum leptin among postmenopausal women. Climacteric 15: 611-620.

22. Silva A, Queiroz SS, Andersen ML, Mônico-Neto M, Campos RM, et al. (2013) Passive body heating improves sleep patterns in female patients with fibromyalgia. Clinics (Sao Paulo) 68(2): 135-140.

23. Özdamar K (2003) Modern scientific research methods. Eskișehir: Kaan Bookstore. Pp: 117

24. (2014) National Center for Complementary and Alterative Medicine What is the CAM

25. Hilditch JR, Lewis J, Peter A, A Ross, E Franssen, et al. (1996) A menopause-specific quality of life questionnaire: developmentand psychometric properties. Maturitas 24(3): 161-175.

26. Kharbouch BS, Şahin HN (2007) Determination of the Quality of Life During Menopausal Stages. Florence Nightingale Jornal of Nursing 15 82-90.
27. Buhling KJ, Daniels BV, Studnitz FS, Eulenburg C, Mueck AO (2014) The use of complementary and alternative medicine by women transitioning through menopause in Germany: results of a survey of women aged 4560 years. Complement TherMed 22(1): 94-98.

28. (2014) T.R. Ministry of Health, Health Surveys General Directorship, Women's Health Research 2014.

29. Merghati-Khoei E, Sheikhan F, Shamsalizadeh N, Haghani H, Yousofnia Pasha YR, et al. (2014) Menopause Negatively Impacts Sexual Lives of Middle-Aged Iranian Women: A Cross-Sectional Study. J Sex Marital Ther 40(6): 552-560

30. Li L, Wu J, Pu D, Zhao Y, Jian Jiang, Naimei Luo, et al. (2012) Factors associated with the age of natural menopause and menopausal symptoms in Chinese women. Maturitas 73(6): 354-360.

31. Posadzki P, Watson LK, Alotaibi A, Ernst E (2013) Prevalence of use of complementary and alternative medicine (CAM) by patients/consumers in the UK: systematic review of surveys. J Clin Med 13(2): 126-131.

32. Cardini F, Lesi G, Lombardo F, van der Sluijs C, MSCG - Menopause Survey Collaborative Group (2010) The use of Complementary and Alternative Medicine by women experiencing menopausal symptoms in Bologna. BMC Women's Health 10: 7 .

33. Sluijs CP, Bensoussan A, Liyanage L, Shah S (2007) Women's health during mid-life survey: the use of complementary and alternative medicine by symptomatic women transitioning through menopause in Sydney. Menopause 14(3 pt 1): 397-403.

34. Koc Z, Saglam Z, Topatan S (2013) Determination of the use of complementary and alternative medicine by women in the climacteric period in the Turkish city of Samsun. Contemp Nurse 45(2): 197-209.

35. Gold EB, Bair Y, Zhang G, Utts J, Greendale GA, et al. (2007) Crosssectional analysis of specific complementary and alternative medicine (CAM) use by racial/ethnic group and menopausal status: the Study of Women's Health Across the Nation (SWAN). Menopause 14(4): 612-623.

36. Sagkal T, Demiral S, Odabas H, Altunok E (2013) Complementary and Alternative Treatment Methods Among Elderly Individuals in Living Rural Setting. Firat University Health Sciences and Medical Journal 27: $19-26$

37. (2014) T. C. Ministry of Health, Traditional, Complementary and Alternative Medicine Practices Department.

38. Morelli V, Naquin C (2002) Alternative therapies for traditional disease states: menopause. Am Fam Physician 66(1): 129-135

39. Kim MY, Choi SD, Ryu A (2015) Is Complementary and Alternative Therapy Effective for Women in the Climacteric Period? J Menopausal Med 21(1): 28-35.

40. Lethaby A, Marjoribanks J, Kronenberg F, Roberts H, Eden J, et al. (2013) Phytoestrogens for menopausal vasomotor symptoms. Cochrane Database of Syst Rev 10 (12): CD001395.

41. Thompson EA (2010) Alternative and complementary therapies for the menopause: A homeopathic approach. Maturitas 66(4): 350-354.

42. Taavoni S, Darsareh F, Joolaee S, Haghani H (2013) The effect of aromatherapy massage on the psychological symptoms of postmenopausal Iranian women. Complement Ther Med 21(3): 158163.

43. Caputo EL, Costa MZ (2014) Influence of physical activity on quality of life in postmenopausal women with osteoporosis. Rev Bras Reumatol 54(6): 467-473. 